\title{
Corrigendum
}

\section{The Oslo University Adolescent and Young Adult Twin Project: Recruitment and Attrition - CORRIGENDUM}

\section{S. Torgersen and T. Waaktaar}

https://doi.org/10.1017/thg.2019.51, Published by Cambridge University Press, 8 August 2019

Keywords: Twins; sample recruitment; attrition; personality; Big Five; HIPIC; DSM-IV clinical conditions; personality disorders

The authors regret that a number in the Abstract is slightly wrong, and that four percentages and one number is wrong in one table.

The number 1422 shall be 1425 in the sentence 'Of these, again 1538 twin families (61.9\%) actually participated in at least one wave and twins from 1425 (57.3\%) participated in the interview’ in line 10-11, page 641. The percentage (57.3\%) is correct.

The column of percentages for FMZ in Table 4 was simply a repetition of the column of percentages for MMZ. Furthermore, the 'Sum' of 'Total number interviewed' was 1425, not 1725 (See correct Table 4).

Table 4. Number (\%) of twin pairs participated in the wave of data collection and/or interview by sex and zygosity (corrected)

\begin{tabular}{|c|c|c|c|c|c|c|c|c|c|c|c|c|}
\hline & \multicolumn{2}{|c|}{ MMZ } & \multicolumn{2}{|c|}{ FMZ } & \multicolumn{2}{|c|}{ MDZ } & \multicolumn{2}{|c|}{ FDZ } & \multicolumn{2}{|c|}{ ODZ } & \multicolumn{2}{|c|}{ SUM } \\
\hline & $n$ & $\%$ & $n$ & $\%$ & $n$ & $\%$ & $n$ & $\%$ & $n$ & $\%$ & $n$ & $\%$ \\
\hline At least one wave, no Interview & 64 & 19.5 & 46 & 14.0 & 64 & 19.5 & 45 & 13.7 & 109 & 33.2 & 328 & 100.0 \\
\hline At least one wave and Interview & 166 & 13.7 & 297 & 24.5 & 161 & 13.3 & 237 & 19.6 & 349 & 28.8 & 1210 & 100.0 \\
\hline Interview only & 31 & 14.4 & 52 & 24.2 & 27 & 12.6 & 32 & 14.9 & 73 & 34.0 & 215 & 100.0 \\
\hline Total number interviewed & 197 & 13.8 & 349 & 24.5 & 188 & 13.2 & 269 & 18.9 & 422 & 29.6 & 1425 & 100.0 \\
\hline
\end{tabular}

Note: MMZ, Male monozygotic; FMZ, Female monozygotic; MDZ, Male dizygotic; MDZ, Male dizygotic; FDZ, Female dizygotic; ODZ, Opposite sex dizygotic.

\section{Reference}

Torgersen, S., \& Waaktaar, T. (2019). The Oslo University Adolescent and Young Adult Twin Project: Recruitment and Attrition. Twin Research and Human Genetics, 22(6), 641-646. doi: 10.1017/thg.2019.51 